Vantage: Journal of Thematic Analysis

ISSN: 2582-7391

A Multidisciplinary Publication of Centre for Research,

Maitreyi College, University of Delhi

April 2021, Volume 2, Issue 1

Excerpts from DRDO Newsletters

\title{
Role of DRDO Developed Technologies/Products for Combating COVID-19
}

\author{
Sanjay Mohan Gupta*
}

Defence Institute of Bio-Energy Research (DIBER), DRDO, Haldwani-263139,

Uttarakhand, India

*Correspondence: gupta@ diber.drdo.in

\section{INTRODUCTION}

In the ongoing efforts against COVID-19 pandemic, DRDO has been using scientific endeavors to develop various technologies/ products in an accelerated manner like other leading public and private research organizations of the Government of India. DRDO laboratories are working in a $24 \times 7$ manner with the possibility of producing spin-off technologies/ products and also collaborating with industry partners for their volume production geared to support the national mission to combat COVID-19. As a result of these efforts, DRDO is ready with some technologies/ products that can be utilized for combating COVID-19.

DIBER is a premier R\&D institute of DRDO engaged in the processing of bio-resources for its judicious utilization and development of technologies and products in the area of Bioenergy, biofuel, bio-fence, camouflage, herbal health products, soil less and protected cultivation for addressing defence needs. A large number of agro-animal technologies specific for mid to high hills of Central Himalaya region have been developed by

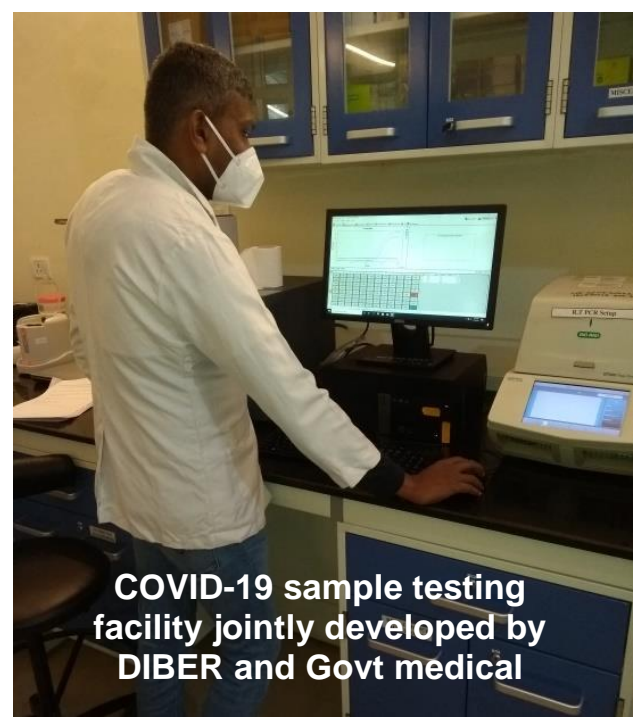


DIBER (erstwhile DARL) and demonstrated to border villagers. DIBER had developed Himalayan medicinal and aromatic plants (MAPs) field gene banks at different locations of DIBER viz. Pithoragarh (5500' asl; asl: above sea level), Auli (9000’ asl) and Haldwani (1400' asl) for ex-situ conservation of valuable Himalayan herbs that have tremendous potential for development of various herbal formulations for curing various diseases including COVID-19 in future. In order to prevent the spread of COVID-19 infection, timely detection of suspected persons is very important for breaking corona infection chain. In this regard, due to limited available facilities for COVID testing in Uttarakhand, DIBER received a request from the Director, 'National Health Mission' in March, 2019 to join hands with Dr. Sushila Tewari, Govt. Medical College and Hospital, Haldwani for testing of COVID-19 suspected samples. After that, DIBER shared its RT-PCR machine along with one of the working expert scientists with medical college, Haldwani and started working from March, 2019 onwards. So far we have jointly tested more than 2 lakhs suspected COVID-19 samples.

Recently, the sincere scientific and technical contributions made by all DRDO laboratories have resulted into development of various technologies/ products that may help in combating COVID-19. Since, each DRDO lab has different expertise and domain area of research, therefore, a joint team work is required to combat COVID-19 pandemic disease. This report highlights some of the DRDO developed potential technologies and information about innovative products/services that are being provided to local administrations, on request, for fighting COVID-19.

\section{DRDO DEVELOPED TECHNOLOGIES/PRODUCTS}

The sincere efforts made by DRDO for combating COVID-19 resulted into development of following technologies/products:

\subsection{Mobile testing lab for COVID-19 detection}

Mobile Virology Research and Diagnostics Laboratory (MVRDL) was developed by Research Centre Imarat (RCI), the Hyderabad-based laboratory of DRDO, in consultation with ESIC Hospital, Hyderabad. The Mobile Viral Research Lab is the 
combination of a BSL 3 lab and a BSL 2 lab. The labs are built as per WHO and ICMR Bio Safety Standards to meet international guidelines. The system has builtin electrical controls, LAN, telephone cabling and CCTV. The Mobile Laboratory will be helpful to carry out diagnosis of COVID-19 and also virus culturing for drug screening, convalescent plasma derived therapy, comprehensive immune profiling of COVID-19 patients towards vaccine development

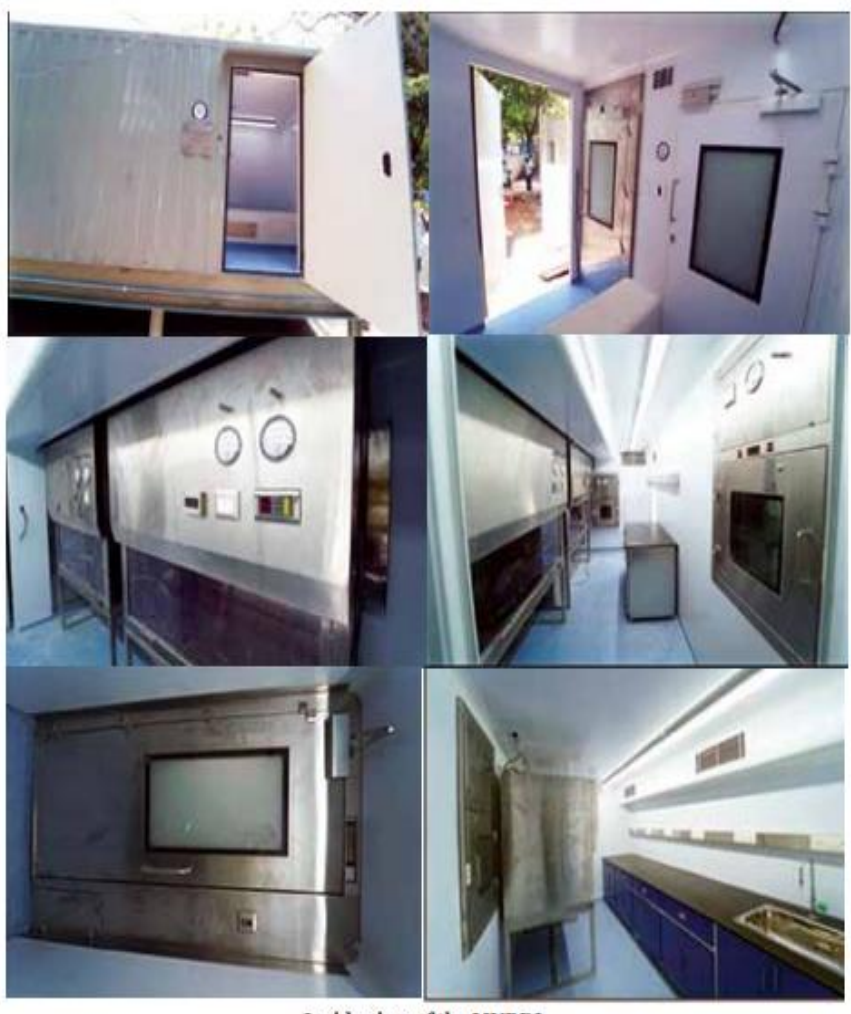

Inside view of the MVRDL and for early clinical trials specific to Indian population. The developed laboratory may screen 1000-2000 samples per day and can be stationed, as per requirement, anywhere in the country.

\subsection{COVID-19 sample collection Kiosk (COVSACK)}

COVID Sample Collection Kiosk (COVSACK) unit has been developed by Hyderabad-based Defence Research and Development Laboratory in consultation with the doctors of Employees' State Insurance Corporation (ESIC), Hyderabad. The COVSACK is a kiosk for use by healthcare workers for taking COVID-19 samples from suspected infected patients. Patient under test walks into the kiosk and a nasal or oral swab is taken by a healthcare professional from

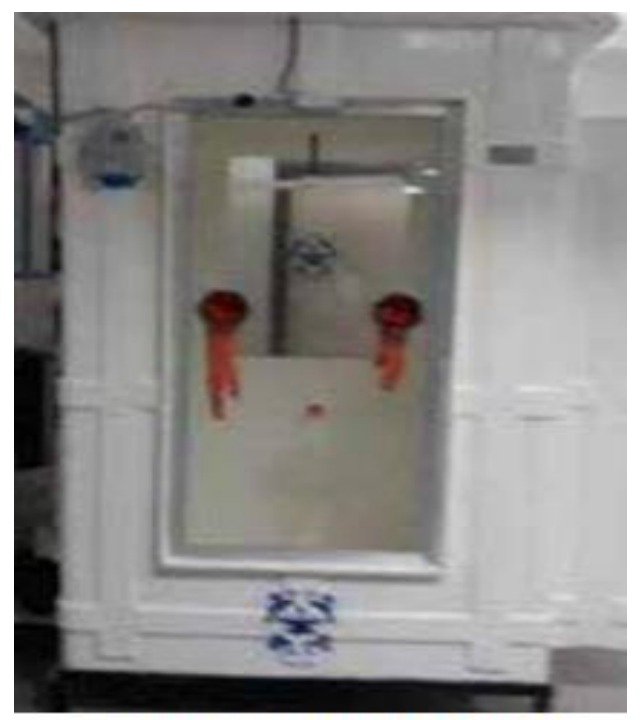

COVID Sample Collection Kiosk 
outside through the built in gloves. The DRDO has designed and developed two units and handed over these to ESIC Hospital, Hyderabad after successful testing.

\subsection{Bio-suit}

Defence Research and Development Establishment (DRDE), Gwalior has developed Bio Suits, which has been produced by three industry partners namely $\mathrm{M} / \mathrm{s}$ Shiva Texyarn, Coimbatore, M/s Arvind Mills, Ahmedabad and M/s Aeronav, Noida and is being supplied to Ministry of Health and Family Welfare (MoHFW), Government of India. Aerial Delivery Research and Development Establishment (ADRDE), Agra and Institute of Nuclear Medicine and Allied Sciences (INMAS), Delhi have also developed

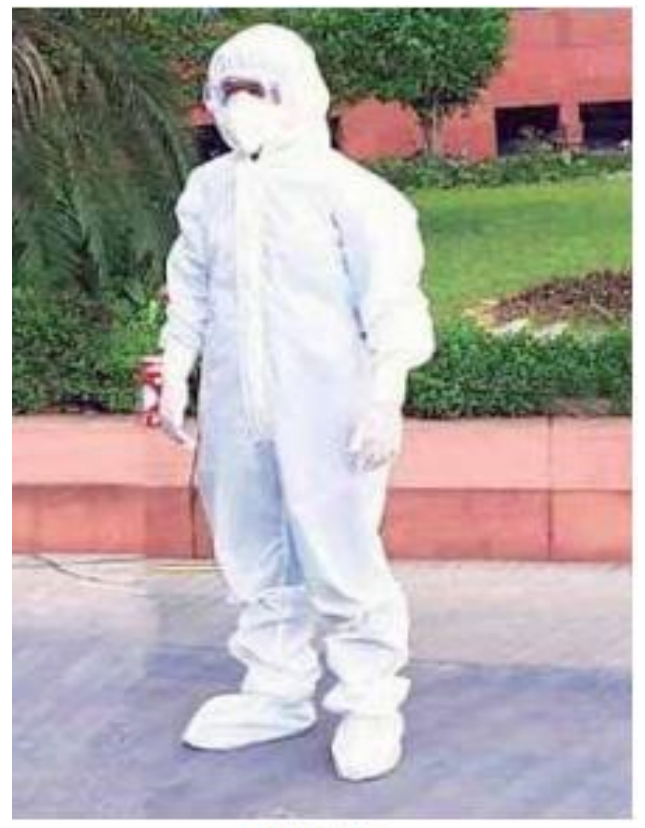

Bio Suit

Bio Suits for protection of medical professionals and paramedics handling COVID-19 patients. The suits are being prepared with the help of the industry after being subjected to rigorous testing for textile parameters as well as protection against synthetic blood. Efforts are being made to ramp up production to $\sim 15,000-20,000$ Personal Protective Equipment (PPEs) per day. 


\subsection{Ventilators}

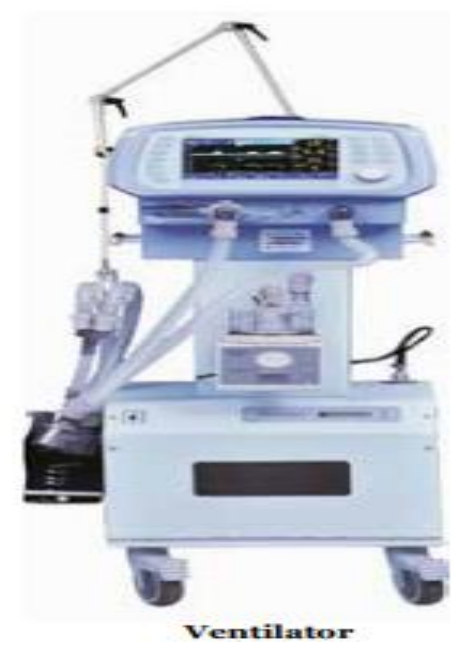

Society for Biomedical Technology (SBMT), a DRDO funded and managed initiative and Defence Bioengineering and Electromedical Laboratory (DEBEL), Bengaluru, have developed a ventilator by using existing technologies like breath regulators, pressure/flow sensors, etc. DRDO has also developed Multi Patient Ventilation (MPV) Kit, which helps convert single ventilators for providing treatment to multiple patients in the emergency.

\subsection{Face masks}

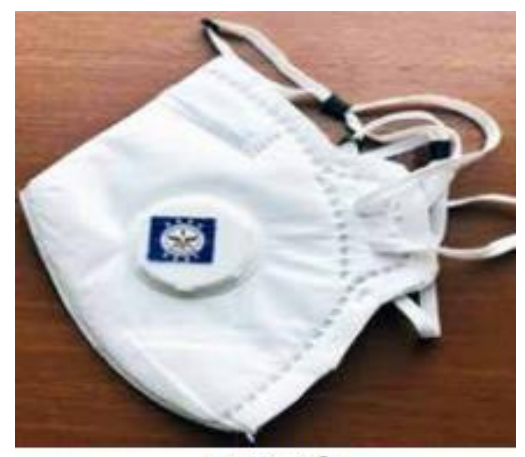

Defence Research and Development Establishment (DRDE), Gwalior has developed five layered N-99 masks using a nano web filter layer. Manufacturing of the masks is in progress with an aim to produce 2 lakh N-99 masks per week through the industry. Institute of Nuclear Medicine and Allied Sciences (INMAS), Delhi has also designed a 3-ply surgical mask for distribution

to Delhi Police and other agencies.

\subsection{Aerosol containment box}

Research Centre Imarat (RCI), Hyderabad and Terminal Ballistic Research Laboratory (TBRL), Chandigarh have come up with Enclosure for Intubation Procedure-Aerosol Containment Box to safeguard health care workers. The enclosure prevents spread of viral contamination of COVID19 to reach the gown, gloves, face mask, eye shield

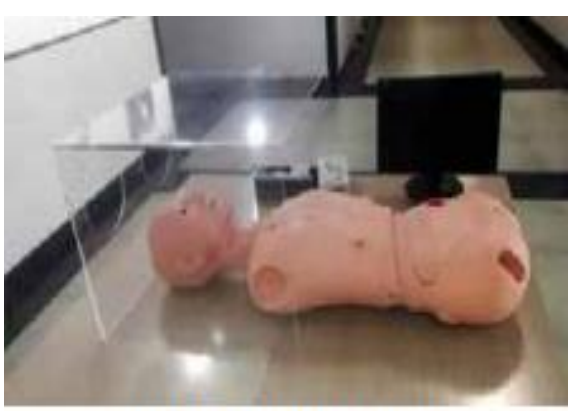

Aerosol Containment Box and shoes of the front line workers. The transparent acrylic/ Polymethyl MethAcrylate (PMMA) box covers the patient's head up to the chest and acts as a safety barrier against 
droplets from patients while under treatment. The design of the enclosures has been validated by a team of doctors at ESI Medical College, Hyderabad and at PGIMER, Chandigarh, respectively.

\subsection{Sanitiser formulation}

To address the need for personal and surface decontamination, DRDE, Gwalior and Centre for Fire, Explosive and Environment Safety (CFEES), Delhi have prepared hand sanitizer compliant to WHO guidelines for local production. More than 1,50,000 bottles of sanitizer based on Isopropyl Alcohol/ Ethanol have been produced in-house and supplied to users. DRDO Laboratories across the country are producing a large amount of hand sanitizers

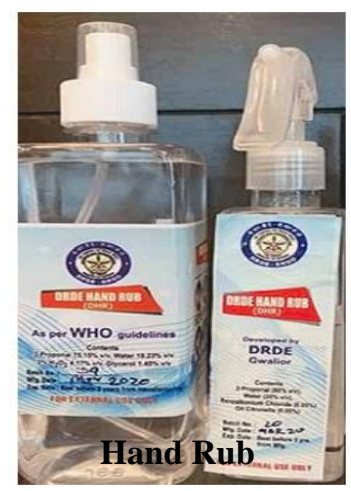
based on DRDE, guidelines and distributing to local administration to fight the pandemic.

\subsection{Sanitization equipments}

The Centre for Fire, Explosives \& Environment Safety (CFEES), Delhi has developed two configurations of sanitizing equipment spin-offs from technologies developed for fire suppression applications. A portable sanitizing equipment has been developed with the help of industry partners for spraying decontamination solution consisting of $1 \%$ Hypochlorite (HYPO) for sanitization of suspected areas. Also, the higher capacity Trolley Mounted Large Area Sanitization Equipment incorporates low pressure single fluid (disinfectant liquid) technology for generating very fine mist. The system is capable of disinfecting an area of up to 3000 square meter. It has a tank capacity of 50 litres and has a lancing (throw) distance of 12-15 meter. In addition, Automatic Mist Based Sanitizer Dispensing Unit has developed automatic mist based sanitiser. By using this, only 5-6 ml sanitizer is released for 12 seconds in one operation that gives the full cone spray over both palms so that the disinfection of hands is complete. 


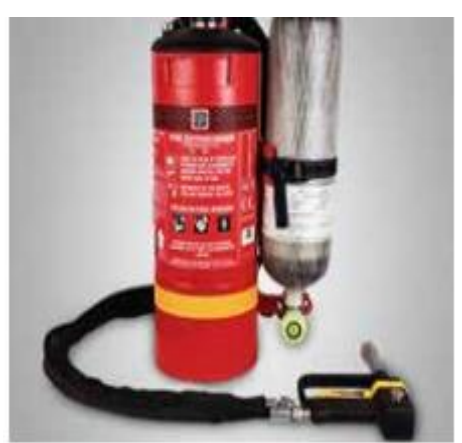

Backpack Area Sanitization Equipment

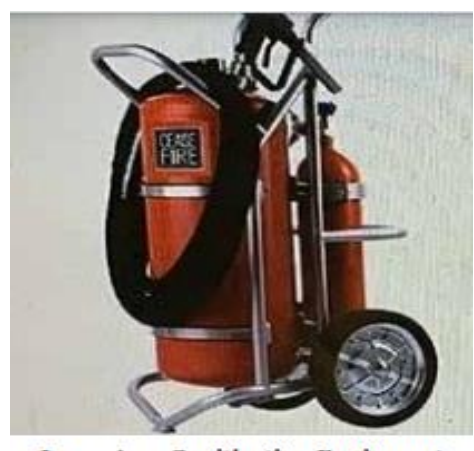

Large Area Sanitization Equipment

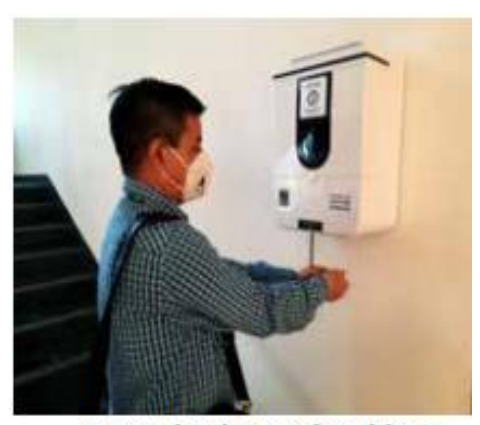

Automatic Mist Based Sanitizer Dispensing Unit

\subsection{UV sanitization box and hand-held UV device}

Defence Institute of Physiology \& Allied Sciences (DIPAS) and INMAS, have designed \& developed ultraviolet C light-based sanitisation box and hand-held UV-C (ultraviolet light with wavelength 254 nanometres) device. The UV-C box is designed for disinfecting personal belongings like mobile phone, tablets, purse, currency, cover of office files, etc. COVID-19 virus will be deactivated by using UVC lamps in one minute placed equidistantly in a box with UV dose of $100 \mathrm{~mJ} / \mathrm{cm}^{2}$. Also, the hand-held device that has eight watt UV-C lamp disinfects office and household objects like food packets, furniture, etc., with an exposure of 45 seconds at a $100 \mathrm{~mJ} / \mathrm{cm}^{2}$ irradiation placed at a distance of less than two inches. This measure can reduce the transmission of COVID-19 infection in office and public places.

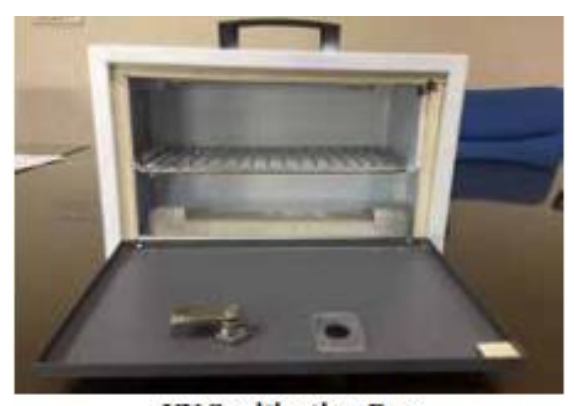

UV Sanitization Box

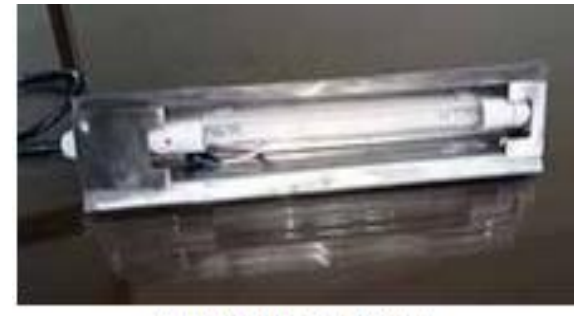

Hand-held UV Device

\subsection{Personnel sanitization station}

The entry point walk through enclosure for personnel decontamination has been designed by Vehicle Research and Development Establishment (VRDE) and developed by M/s DH Ltd., Ghaziabad. VRDE has conceptualized this low pressure mist system for individual sanitization installed in a MS container based cabin. This can be easily mounted on a vehicle, transported and refabricated within two hours. 


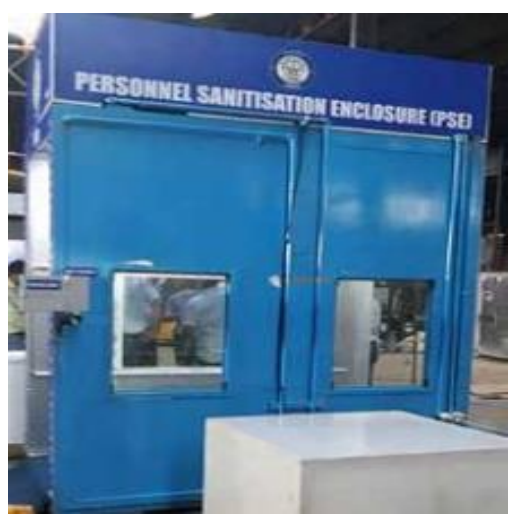

Personal Sanitization Enclosure

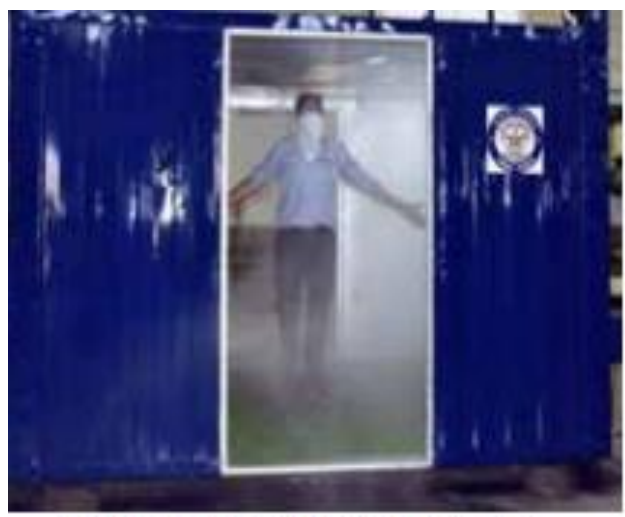

Personnel Sanitization Station

\subsection{Low cost vehicle sanitization enclosure}

This system is lightweight, portable canopy and can be made operational in three hours to sanitize vehicles at entry points of premises. An electrically operated positive displacement pump creates disinfectant mist inside the tent canopy through which the vehicles are passed. A $500 \mathrm{~L}$

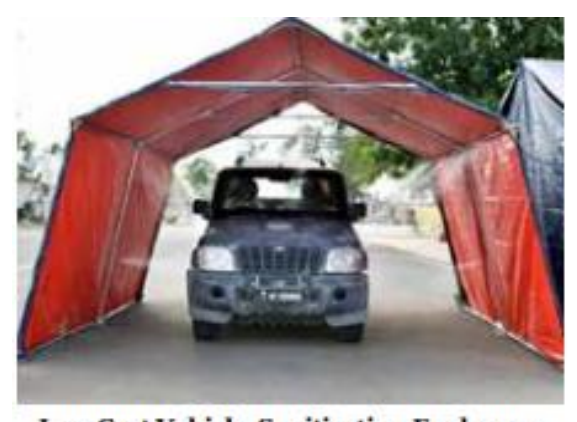

Low Cost Vehicle Sanitization Enclosure separate tank, stores disinfectant, which is sufficient for disinfection of $\sim 200$ vehicles at one time.

\subsection{Quarantine facility}

To fight pandemic COVID-19, VRDE has reorganized one of its buildings to be utilized as a 50-bed quarantine facility for confirmed/ suspected COVID-19 patients of Ahmednagar District.

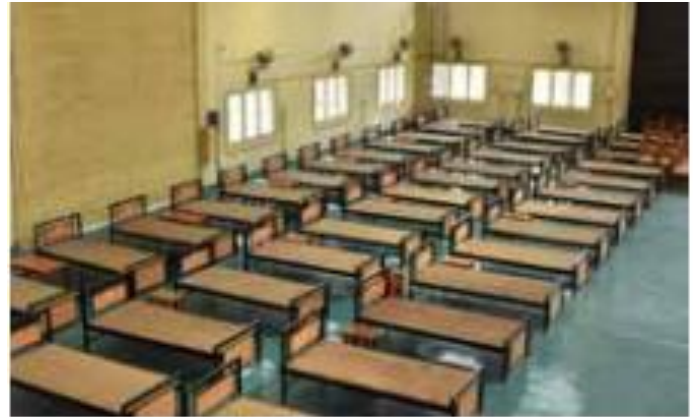

Quarantine Facility

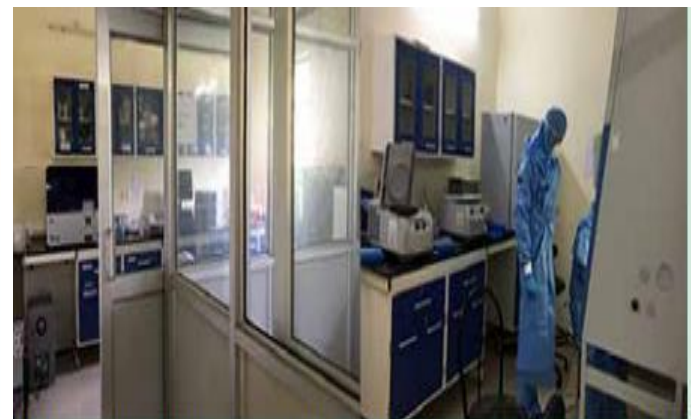

DIBER scientists at work for detection of COVID-19 at Goot Medical College, Haldwani

\subsection{Protective face shield}


Research Centre Imarat (RCI) Hyderabad, TBRL, Chandigarh and HPO-1, DRDO HQ, New Delhi has developed face protection shields for health care professionals and security forces handling COVID-19 patients. All the designs are lightweight and have negligible aerosol movement at face to minimize contamination from direct splash and sneezing. The face mask is being mass produced using injection moulding technique at Delhi, Chandigarh, Hyderabad and Bengaluru. A total capacity of approximately 2 lakh units

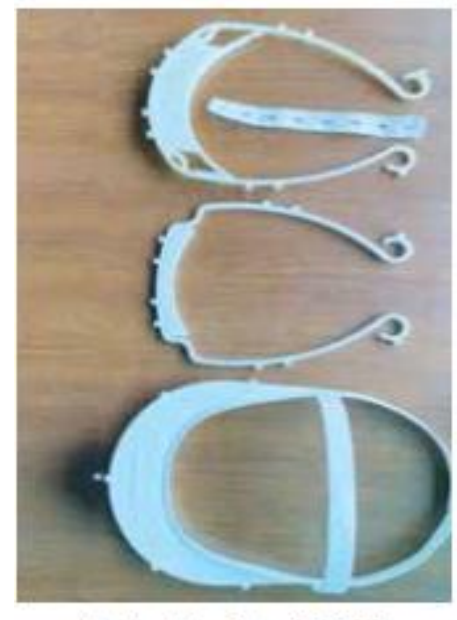

Protective Face Shield of face shields per day has been created within a short span of time to meet urgent requirements.

\subsection{DRDO labs help in testing \& diagnosis of COVID-19}

\section{DIBER joins National Health Mission in}

Uttarakhand to strengthen the existing diagnostic medical facilities at Government Medical College, Haldwani. Defence Institute of Bio-Energy Research (DIBER), Haldwani, promptly rose to the occasion and is working $24 \times 7$ with the team of VRD Lab of Government Medical College since $26^{\text {th }}$ March, 2020.

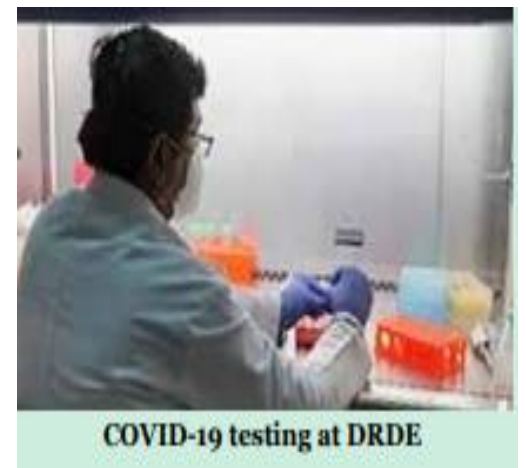

All the tests are being carried out as per SOPs of Indian Council of Medical Research (ICMR). DIBER has also extended the infrastructure support by providing its calibrated functional CFX-96 RT-PCR machine and necessary peripherals to the Government Medical College. So far, more than 2 lakhs COVID-19 samples have been tested successfully. Also, DRDO chips in as a Detection Centre; DRDE, Gwalior is functioning as a Centre for Detection of COVID-19 positive cases from samples provided by Madhya Pradesh Health Service. DRDE has the potential to perform confirmatory tests akin to National Institute of Virology (NIV), Pune.

\subsection{DRDO builds 1000-bed temporary COVID Hospital in 12 days}


The facility was built in a record time of 12 days by DRDO along with Ministry of Home Affairs (MHA), Ministry of Health and Family Welfare (MoHFW), the Armed Forces, Tata Sons and other industry players.

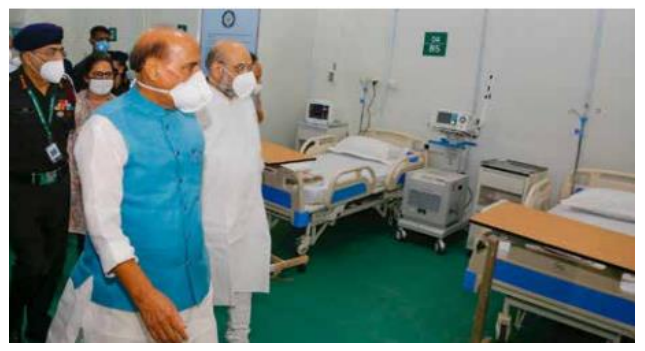

2.16. DRDO's 500 bed COVID Hospital was inaugurated in Patna

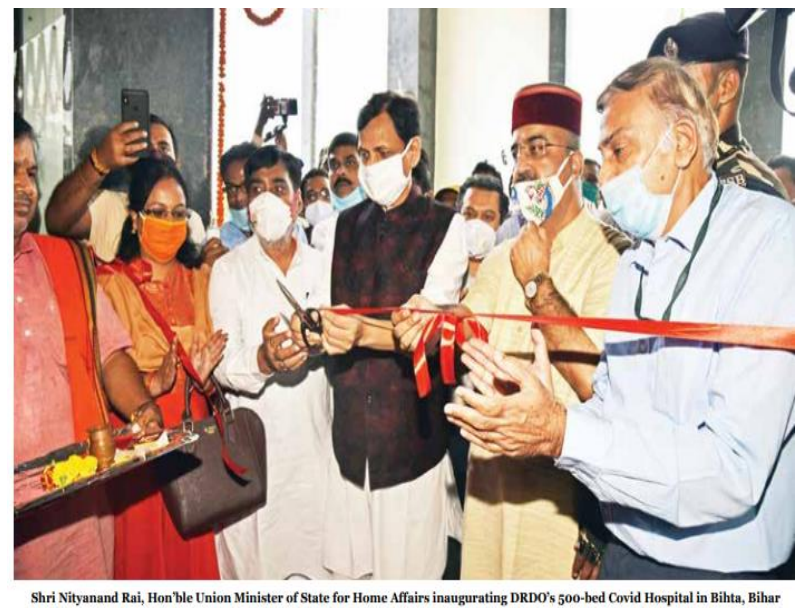

A 500 bed COVID-19 Hospital with 125 ICU beds, set up by DRDO in Patna was inaugurated on 24 August 2020 by Shri Nityanand Rai, Hon'ble Union Minister of State for Home Affairs. The hospital located in the newly constructed ESIC Hospital at Bihta, has been built on the lines of the 1000 Bed Sardar Vallabhbhai

Patel Hospital at Delhi Cantonment built by DRDO.

\subsection{Course on CBRN Emergency Management}

Institute of Nuclear Medicine \& Allied Sciences (INMAS), Delhi conducted an Online Training Course on "CBRN Emergency Management with Specific Reference to COVID-19" from 5-9 October, 2020 through virtual platform DEEKSHA developed by DESIDOC, Delhi.

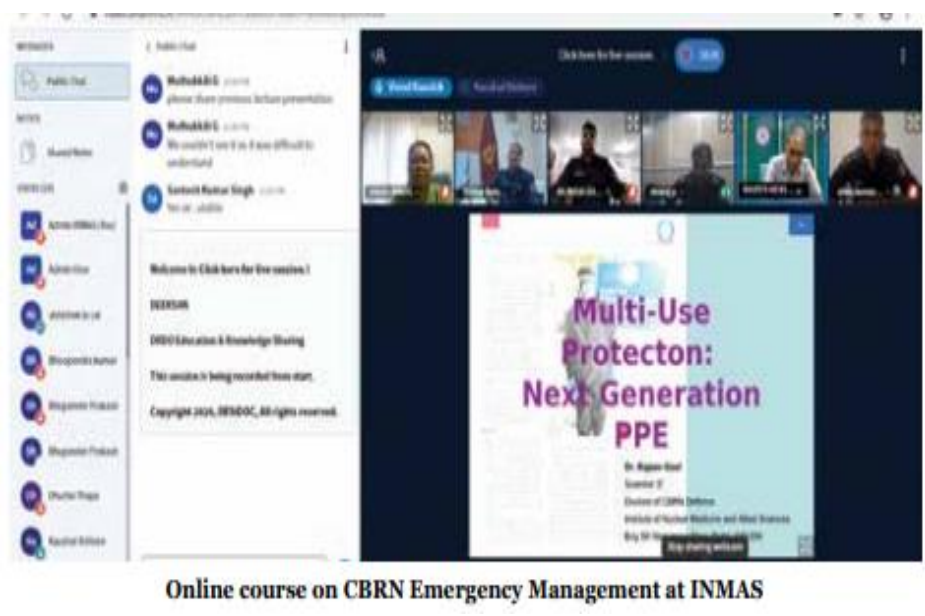




\section{CONCLUSION}

The sincere scientific and technical contributions made by all DRDO laboratories for developing various technologies/ products specific for combating COVID-19 pandemic is appreciable. However, each lab has its own expertise and domain area of research, therefore, a joint venture is required as team work to fight against COVID-19. The discussed COVID-19 specific DRDO contributions are just beginning and many more may yet to come in future. We are confident that the scientific knowledge and expertise of DRDO scientific and technical staff will surely develop more technologies /products in the coming future that may help in combating COVID-19 pandemic disease.

\section{ACKNOWLEDGMENT}

Defence Research and Development Organization (DRDO), Ministry of Defence, Government of India is duly acknowledged for their scientific and technical efforts made for development of technologies/ products for combating COVID-19.

\section{CONFLICT OF INTEREST: None.}

\section{REFERENCE}

DRDO Newsletters. (2019-2020). DRDO, Headquarters, New Delhi.

How to cite this article: Mohan, S. (2021). Role of DRDO Developed Technologies/ Products for Combating COVID-19. Vantage: Journal of Thematic Analysis, 2(1): 106116.

DOI: https://doi.org/10.52253/vjta.2020.v02i01.07

(C) The Author(s) 2021.

This work is licensed under a Creative Commons Attribution 4.0 International License which permits its use, distribution and reproduction in any medium, provided the original work is cited. 